The University of Maine

DigitalCommons@UMaine

Publications

Senator George J. Mitchell Center for Sustainability

Solutions

6-2016

\title{
Efficiency and Detection Accuracy Using Print and Digital Stereo Aerial Photography for Remotely Mapping Vernal Pools in New England Landscapes
}

Fred J. DiBello

Aram J K Calhoun

University of Maine, Calhoun@maine.edu

Dawn E. Morgan

Amanda F. Shearin

Follow this and additional works at: https://digitalcommons.library.umaine.edu/ mitchellcenter_pubs

\section{Repository Citation}

DiBello, Fred J.; Calhoun, Aram J K; Morgan, Dawn E.; and Shearin, Amanda F., "Efficiency and Detection Accuracy Using Print and Digital Stereo Aerial Photography for Remotely Mapping Vernal Pools in New England Landscapes" (2016). Publications. 15.

https://digitalcommons.library.umaine.edu/mitchellcenter_pubs/15 
Remotely Mapping Vernal Pools in New England Landscapes

Fred J. DiBello ${ }^{1}$ Aram J. K. Calhoun², Dawn E. Morgan ${ }^{3}$, Amanda Shearin $^{4}$

Fred J. DiBello

fred.dibello@stantec.com

Aram J. K. Calhoun

calhoun@maine.edu

Dawn E. Morgan

dawn.morgan@maine.edu

Amanda F. Shearin

amanda.f.shearin@maine.gov

${ }^{1}$ Stantec Consulting Services, Inc., 30 Park Drive,

Topsham, ME 04086, USA

${ }^{2}$ Department of Wildlife, Fisheries, and Conservation Biology,

University of Maine, Orono, ME 04469, USA

${ }^{3}$ Northern Forest Conservation Services, 260 Wylie Hill Road, Craftsbury Common, VT 05827, USA

${ }^{4}$ Maine Department of Inland Fisheries and Wildlife, 41 State House Station, Augusta, ME 04333, US 
Abstract

Aerial imagery has been used to identify potential vernal pools (PVPs) using stereo photographic prints. Stereo plotter photogrammetry now allows digital aerial images to be viewed in stereo (3-Dimensional) to enhance remote sensing capabilities. We used both print and digital imagery to mapPVPsin10townsinMaine, USA. We used field verification of 771PVPs to explore efficiency and accuracy of the two methodologies and to determine effects of pool size and land cover on accuracy. We compared known pool locations with National Wetland Inventory (NWI) data. The stereo plotter was more efficient and easier to use than prints. In the towns where print imagery was used, $77.4 \%$ of surveyed PVPs were confirmed as comparedto60.8\%ofPVPs surveyed in the towns with digital photography. The higher commission errors using the digital method were likely due to enhanced ability to detect smaller features. Omission errors were common using both print and digital methods. Only 43\%ofconfirmedvernalpoolswerelocatedinareas mapped by NWI, suggesting that NWI information does not improve detection accuracy. Aerial photo interpretation continues to be effective for PVP identification in our region and is improved with the use of digital stereo plotters.

Keywords:

Vernal pools, Mapping, Aerial photography, Stereo plotter, Detection accuracy, Maine 
Introduction

Effective management of natural resources typically begins with resource identification and mapping. For temporary wetlands, including vernal pools, remote identification can be challenging. However, absence of these data can be a significant road block to conservation efforts. Aerial photo interpretation has been used to remotely identify larger wetlands for decades, as exemplified in the US Fish and Wildlife Service's National Wetland Inventory (NWI) program, an initiative to map and classify the Nation's wetlands (Cowardin et al. 1979; Tiner 1984).More recently, efforts have been made to remotely identify and inventory smaller wetlands, including vernal pools (Brooks et al. 1998;Burne 2001; Lathrop et al. 2005; Oscarson and Calhoun 2007; Carpenter et al. 2011). Aerial photo interpretation has proven to be an appropriate and comparatively cost-effective first step to identify vernal pools over large geographic areas where field surveys would be either impractical (e.g., too remote or on privately owned lands requiring permission for access) or financially prohibitive (Lathrop et al. 2005; Burne and Lathrop 2008; Van Meter et al. 2008).Although aerial photo interpretation is known to either underestimate pool numbers(omission) or include features that are not pools(commission), particularly in dense, forested canopy cover (Tiner 1990;Calhoun et al.2003), it is nonetheless considered a useful first step in an inventory and assessment program (Morgan and Calhoun 2013).

Vernal pools have typically been mapped by interpreting aerial photography using either $22.9 \mathrm{~cm} \times 22.9$ $\mathrm{cm}$ analog stereo-coverage aerial photo prints viewed in three dimensional (3D) format under a stereoscope (Stone 1992; Barrette et al. 2000; Calhoun et al.2003; Burne and Lathrop 2008), or 2D digital orthophoto maps using standard computer monitors and GIS (geographic information system) software (see Lathrop et al. 2005). Recent advances allow on-screen 3D viewing of digital aerial photography processed with digital terrain model (DTM) data to provide reduced distortion and increased mapping accuracy(see Maguire et al. 2012; Murillo-García et al. 2014 for applications to other resources). Accuracy and efficiency of photo-interpretation vary among these three methods. In analog photos, the horizontal scale is typically distorted along the outer 
portions of the prints, so errors in scale, location, and feature shape (positional accuracy) are easily introduced to the mapping process. Use of 2D orthophotos increases positional accuracy, obviates the need for obtaining and handling photo prints, and allows on-screen digitizing of vernal-pool boundaries directly to GIS. However, the lack of 3D viewing capabilities eliminates the vertical dimension and makes vernal pool detection inherently more difficult. Detection accuracy is an important consideration regardless of the method, as high rates of omission (up to30\% in some studies) and commission errors (upto50\%) highlight an inherent limitation when using aerial photography to map vernal pools (Tiner 1990;Calhoun et al.2003; Lathropet al. 2005; Van Meter et al.2008). The efficacy and detection accuracy of 3D viewing and integrated digital mapping with DTM data for remotely sensing vernal pools or other small wetland features has not been discussed in the literature. We were also unable to find efficiency comparisons in the literature among the three methods of remote interpretation; however, analog photo-interpretation typically requires sorting and handling of multiple individual prints (up to 100 or more for a typical town of $100 \mathrm{~km}^{2}$ ), which is inherently time-consuming. Light Detection And Ranging technology (LiDAR) and other remote imaging methods, including SPOT satellite imagery, are currently prohibitively expensive for municipalities or other small private organizations to use for mapping vernal pools in forested regions of the glaciated northeastern North America (but see Haaset al. 2009 for mapping temporary pools in semi-arid environments, and Leonard et al. 2012 and Wu et al. 2014 for use of LiDAR).

In 2006, Maine passed legislation (Natural Resources Protection Act, 38 M.R.S.A. §§ 480-A to 480-FF) regulating a subset of exemplary vernal pools based on key biological criteria (e.g., egg mass abundances of indicator pool-breeding amphibians or presence of state-listed rare species). A number of Maine towns joined a program initiated by Maine Audubon Society and the University of Maine to map and assess vernal pool resources at the municipal scale. The Maine Vernal Pool Mapping and Assessment Program (VPMAP; see Morgan and Calhoun 2013) relied on aerial photo-interpretation to identify vernal pools in 13 Maine towns and used trained citizen scientists to field-verify a subset of these features (Jansujwicz et al. 2012, 2013). 
Ten towns took part in the citizen science mapping project: two towns using analog photography and eight towns using digital 3D photography.The vernal-pool maps created for this program presented an interesting opportunity for us to use an existing set of data to explore the efficiencies and accuracy of two easily available and affordable methods of photointerpretation of vernal pools: analog and 3D digital stereo. Had we designed the project to look at these differences, we would have tested both methods in multiple towns. However, given the data set was existing, we took advantage of this opportunity to fill in a literature gap addressing issues of efficiency and detection accuracy. In this paper we:(1) look at the efficiency (level of effort and hence cost) and detection accuracy(extent of commission and omission errors)of aerial photo interpretation to identify and map vernal pools, comparing analog and digital stereo photographic formats; (2) examine whether factors such as pool size and surrounding land-cover type affect the spatial and categorical accuracy of aerial photo interpretation; and (3) compare known pool locations with NWI data to see whether NWI maps might assist in identifying vernal-pool locations.

\section{Methods}

Study Area

We assessed the remote identification of vernal pools in 10 towns in southern and central Maine, USA (Fig. 1), representing approximately $839 \mathrm{~km}^{2}$ of land area. Individual town sizes range from $35 \mathrm{~km}^{2}$ to nearly 130 $\mathrm{km}^{2}\left(\right.$ mean $\left.=84 \mathrm{~km}^{2}\right)$. Eight towns were adjacent to or within $16 \mathrm{~km}$ of the Atlantic coast, while two were located approximately $65 \mathrm{~km}$ inland. Even though the towns were somewhat spread out over the land scape, they occupied the same region and have many physiographic characteristics in common. The study area is situated in the United States Forest Service Laurentian Mixed Forest Province and is characterized as a post-glaciated landscape composed of rolling hills, lakes and poorly drained depressions that form wetlands, including vernal pools. Elevations range from 0 to 730 masl. Forest cover in each of the study area towns typically includes a mix 
of coniferous and deciduous species, though pure coniferous or deciduous stands are not uncommon. Common conifers include eastern white pine (Pinus strobus Linnaeus), eastern hemlock (Tsuga canadensis L.), balsam fir (Abies balsamea L.), and spruce (Picea glauca Moench and P. rubens Sarg.). Common deciduous trees include red maple (AcerrubrumL.), sugar maple (Acer saccharum Marsh.), American beech (Fagus grandifolia Ehrh.), red oak (Quercus rubra L.), and quaking aspen (Populus tremuloides Michx.). Deciduous shrub cover is found primarily in wetlands, reverting agricultural fields, and maintained clearings (e.g., transmission or pipeline corridors).

Remote Vernal Pool Identification and Mapping

We used images from early spring (April or May), prior to bud swell and leaf emergence on deciduous species, and when surface hydrology is typically at its zenith due to snowmelt and seasonal rain fall. The type of imagery was based primarily on availability and was not specifically chosen by the authors for this comparison. We evaluated 1:12,000 Color Infrared (CIR) analog photography for the towns of Orono and Falmouth, viewing the stereo prints in 3D under a table-top mirror stereoscope with $1.5 \times$ and $3 \times$ optical magnification. For the remaining eight towns, we used digital aerial imagery and digital stereo plotter technology to view the imagery in 3D. The digital aerial imagery types used in this study included: (1) true color film at a scale of 1:7200 and scanned at a resolution of 7.62-cm pixels (seven towns); and (2) CIR film at a scale of 1:7200 and scanned at 15.24-cm pixel resolution (one town). All digital images were orthorectified and georeferenced. Horizontal accuracy of the digital imagery was reported to be within 1-1.5 $\mathrm{m}$. We viewed the imagery using Summit Evolution ${ }^{\mathrm{TM}}$ photogrammetry software from DAT/ EM Systems ${ }^{\circledR}$, which runs simultaneously with $\operatorname{ArcGIS}^{\circledR}$ mapping software to allow on-screen collection of spatial data to create GIS layers. We used a Planar ${ }^{\circledR}$ stereo computer monitor and an enhanced graphics card installed in a desktop computer. 
Because field surveys during the amphibian breeding period are required to document actual use by vernal pool species, pool features identified through remote sensing are hereafter referred to as "potential" vernal pools (PVPs) pending field verification. We based our aerial photo interpretation of PVPs on our field experience with vernal pool ecology in Maine and over 10 years of experience in vernal pool photo-interpretation. Our objective was to identify pools and other inundated areas exhibiting the physical characteristics (i.e., surface water in spring high water) that could potentially support breeding and egg-laying activity by wood frogs (Lithobates sylvaticus), ambystomatid salamanders (Ambystoma spp.), or fairy shrimp (Eubranchipus spp.), all vernal pool indicator species in Maine (Calhoun et al. 2003). Photos were carefully reviewed for pools within both forested and open cover types. We attempted to determine the presence of inlets or outlets, but these features are often not discernable on aerial images. We included natural, altered, and anthropogenic PVP features, and tended to favor inclusion when there was a question about whether an observed feature could potentially function as a vernal pool. We did not include features that were obvious streams or beaver flowages. No attempt was made to evaluate regulatory jurisdiction or whether a feature might fit any strict definition of vernal pools. For consistency, one individual completed all the image interpretation and PVP mapping. Mapping methods differed between analog and digital image formats. For towns with analog photography, we identified PVPs with the stereoscope and outlined their boundaries with a fine-tipped pen on removable clear acetate sheets overlaid on the photo prints. Each PVP was assigned an identification number and we recorded pool type (open pool, shrub, or forested) and suspected pool origin (natural vs. anthropogenic). Using Auto Cad Map ${ }^{\circledR}$ and on-screen methods, we digitized the marked PVP boundaries onto geo-referenced digital CIR mosaics of the respective towns. To minimize boundary-transfer errors in the digitization process, the mosaics were made from the same series of images used for interpretation. From the digitized PVP polygons in CAD, we produced a GIS shape file we used to calculate PVP sizes and location coordinates and to prepare maps for field survey navigation.

For the remaining eight towns, we searched for PVPs using the stereo plotter software and stereo computer monitor to view digital imagery in 3D. As PVPs were identified, we digitized the boundaries on-screen 
directly into town specific GIS shape files. As with analog methods, we assigned a unique ID number for each PVP and recorded the interpreted pool type and origin in the shape files' attribute tables.

We used the digitized PVP polygons to estimate pool sizes, which in our analyses represent an interpretation of the inundated area seen on the aerial photo, not a field measurement. Actual boundaries and sizes would be expected to vary temporally for any given pool, so our data illustrate a snapshot in time. Although we did not assess the accuracy of our PVP size estimates, we would expect it to vary based on many factors including type and clarity of imagery and vegetative cover. Boundary accuracy was likely best in relatively open areas and less so in dense, forested cover, which affected the interpreter's ability to see the entire pool and to distinguish surface water from shadows.

NWI wetland classes based on the dominant vegetation within the pool were determined remotely for each PVP as were estimates of dominant vegetation cover within 30 meters of the PVP boundary, a distance that represents the approximate limit of shadow influence from adjacent tree cover. Land-cover types were categorized as deciduous forest, coniferous forest, mixed deciduous-coniferous forest, or open land. The open land-cover type contained less than $50 \%$ a real canopy cover and included forest openings, shrub growth, fields, roads, development, and other largely treeless areas.

Field Verification of Mapped PVPs

Volunteer citizen scientists for each town were trained to field assess PVPs (methods described in detail in Morgan and Calhoun 2013 [www.vernalpools.me ]). Field assessments were only conducted on pools where landowners granted permission. Due to time constraints, PVPs were typically assessed once unless a second visit in the same year was recommended by volunteers. Field surveys were conducted during peak amphibian 
breeding times and some pools were visited a second time in the subsequent year if initial surveys were inconclusive. Volunteers noted if the PVP they were field-checking was a vernal pool (field-confirmed vernal pool [CVP] exhibiting any level of biological activity), not a pool (field-confirmed non-vernal pool [NVP] either with insufficient hydrology and/or no biological activity), or unable to be located (also considered NVP). For this study, CVP designations were only assigned to features that exhibited both pool hydrology and breeding activity at the time of the field survey. Breeding activity was defined as the presence in the pool of fairy shrimp or one or more egg masses or larvae of at least one amphibian indicator species. Photo documentation showing landscape setting, pool habitat, and evidence of breeding amphibians or presence of fairy shrimp was requested for each PVP visited. Volunteers also noted vernal pools found during the field surveys that were missed by photo interpretation, though these were not mapped as part of the survey protocol. A coordinator in each town collected each volunteer's field data and provided these to the authors.

To facilitate tabulation and data analyses, we first screened the field data and removed unusable records (i.e., duplicate or incomplete information). Acceptable data records included those documenting one or more site visits to an individual PVP where the field observer recorded whether the pool existed, and if so, whether there was evidence of breeding activity by vernal pool indicator species. Errors of commission included those PVP sites that were field-surveyed but reportedly did not contain a pool or, if a pool was present, did not exhibit biological activity by vernal pool species at the time of the survey. Errors of omission included biologically active pools found in field surveys that were not mapped as PVPs by remote sensing.

Statistical Analyses

Comparing Remote Sensing Methods. We considered that an accurate photo interpretation was one that detected and correctly identified a feature as a vernal pool based on field confirmation of suitable hydrology and biological use by vernal pool species (i.e., accuracy = not a commission error). 
Effects of Landscape and Other Pool Factors on Detection Accuracy. We used generalized linear mixed models to describe relationships among landscape characteristics and the likelihood that a remotely identified pool is a CVP. The response term was vernal pool status (CVP or NVP). Among explanatory variables we considered, the fixed effects in our models included PVP size (pool area), pool type (forested, shrub, emergent, or open as determined from our remote sensing), dominant forest cover type (deciduous, coniferous, mixed, or open) within the PVP, and dominant forest cover type adjacent to the PVP. The random variable was Town. Relationships among NWI Data and Confirmed Vernal Pools For the seven towns where we used NWI data, we included NWI wetland type (PUB, PEM, PSS, PFO, or none) in our generalized mixed models as an explanatory variable. We also used Chi-square tests to determine whether CVPs were more likely to occur (1) in NWI mapped wetlands versus NWI uplands, and (2) in certain NWI palustrine types. We examined the relationship among CVP density and NWI palustrine area in each town using Pearson's product moment correlation.

$\underline{\text { Results }}$

Efficiency and Ease of Use

We identified and mapped 2230 PVPs within the 10 towns, requiring approximately $455 \mathrm{~h}$ of remote-sensing effort for $839 \mathrm{~km}^{2}$ of land area (Table 1). Use of digital stereo images and stereo plotter software was more time efficient and easier than using photo prints and a stereoscope for the same tasks. Total level of effort (hours of photo interpretation, digitizing, and mapping) per $\mathrm{km}^{2}$ of search area varied by town from 0.3 to 1.0 (mean $\pm 1 \mathrm{SE}=0.61 \pm 0.07$ ) for the 10 towns. The average time (mean $\pm 1 \mathrm{SE}$ ) for PVP interpretation and mapping using analog photos was $0.92 \pm 0.07 \mathrm{hrs} / \mathrm{km}^{2}$, approximately a $75 \%$ increase in effort over the $0.54 \pm$ $0.07 \mathrm{hrs} / \mathrm{km}^{2}$ using digital photos. 
Detection Accuracy

Detection accuracy of remote sensing was measured by determining the proportion of field-surveyed PVPs exhibiting biological activity in at least one survey year. Field crews surveyed 771 of the photo-interpreted PVPs to assess biological activity, and by chance identified an additional 98 pools in the field (Table 2). Overall, 493 (63.9 \%) field-surveyed PVPs were found to contain biological activity by vernal pool species. The remaining 278 (36.1 \%) surveyed PVPs lacking biological activity or that could not be located in the field are considered errors of commission (Table 3).

In the two towns where analog methods were used, 113 out of 146 (77.4 \%) field-surveyed PVPs were CVPs, whereas 380 out of 625 (60.8\%) PVPs surveyed in the eight towns with digital photography were CVPs. The 98 new pools identified in the field as crews navigated to and from the PVP locations, considered errors of omission, represent approximately $11 \%$ of all field-surveyed features and $20 \%$ of the remotely-identified CVPs.

Factors Affecting Detection Accuracy

For all towns, PVP size (surface area) was a strong predictor of accurate identification as a vernal pool, with larger PVPs having a greater probability of being a vernal pool (Table 4 and Online Resource 1). For illustrative purposes, the 771 field-surveyed PVPs were divided into size classes chosen to represent the range of pool sizes we encountered within the 10 study towns (Fig. 2). The sizes of vernal pools correctly identified by remote sensing range from less than $10 \mathrm{~m}^{2}$ to over $1000 \mathrm{~m}^{2}$. Higher levels of detection accuracy were realized in pools $>100 \mathrm{~m}^{2}$ while lower levels of accuracy (i.e., more commission errors) were generally associated with 
features $<100 \mathrm{~m}^{2}$. Pool type also was retained in our best model predicting PVP detection accuracy, with open pools associated with greater detection accuracy and shrub and forested pools associated with lower detection accuracy. Potential Vernal Pools identified within open cover were more likely to be CVPs than those containing deciduous cover. Potential Vernal Pools adjacent to mixed cover also were more likely to be CVPs than those adjacent to open cover types (Table 4 and Online Resource 2).

Use of NWI Data for Predicting Vernal Pool Occurrence

For the seven towns with available NWI data, NWI information did not improve our ability to predict which PVPs were CVPs (OnlineResource3). There was no correlation between mapped palustrine area and the number of CVPs per $\mathrm{km}^{2}$ of town area $(T=-0.39, \mathrm{df}=5, \mathrm{p}=0.17)$.CVPs were less likely to occur in NWI wetlands $\left(X^{2}=5.83, d f=1, p=0.02\right)$. For CVPs occurring in NWI wetlands, pools occurred equally among PEM, PFO, PSS, and PUB wetlands $\left(X^{2}=5.94, d f=3, p=0.11\right)$. Mapped NWI wetland type was not a strong predictor of field-verified pool type $\left(X^{2}=7.92, d f=6, p=0.24\right)$. Overall, only $43.4 \%$ of CVPs in these towns were located in NWI wetlands, and of 144 known pools whose boundaries fell within NWI wetlands, most (59.1\%) were located in areas mapped as scrub-shrub and forested wetland types, with the remaining occurring in open-water areas (Table 5).

\section{$\underline{\text { Discussion }}$}

Identifying vernal-pool locations over large areas is critical to developing local or regional conservation strategies and management solutions for these important resources. Using 3D aerial photography to accomplish this is a practical and cost-efficient first step. Although aerial photo interpretation has limitations and is not as accurate as field surveys in determining the extent and location of vernal pools, our evaluations show that digital stereo plotter technology is significantly easier and more time and cost-effective than traditional 3D aerial photo 
interpretation methods. We also identified some trends and factors that could be used in future efforts to map vernal pools remotely.

We believe the increased efficiency of the 3D digital methodology was due to the relative ease of organizing, handling, and viewing digital images, and the ability to zoom and pan with the images always in focus. From the perspective of the photo interpreter, stereo digital technology addresses many of the inherent problems we have experienced using stereo prints. We recognize four distinct advantages of using digital imagery and stereo plotter software:

(1) Storage and Retrieval: Because coverage of large geographic areas can require hundreds of images that need to be stored, organized and handled, digital 3D allows for greater work efficiency through electronic file storage and organization, as compared with paper prints stored in boxes or scattered on a work surface.

(2) Viewing in 3D: To view the images in 3D, the stereo plotter software selects the correct stereo pairs for a given location and displays them on the stereo monitor in the correct alignment. The software allows the viewer to pan through multiple, successive stereo pairs, continually displaying the images in 3D and in the correct orientation. This contrasts with the mirror stereoscope method, whereby only one pair of stereo prints can be viewed at one time and prints must be continuously adjusted under the scope to keep them in focus as the photo viewing area changes. We found that the stereo plotter reduced eye fatigue significantly compared to the stereoscope.

(3) Zooming: In contrast to the typical mirror stereoscope's fixed optical magnifications (typically $1.5 \mathrm{x}$ and $3 x)$, stereo plotter software allows a wide range of options, including pre-set zooms and continuous "real-time" zooming. This enables examination of image features close-up (i.e., from a low altitude) or zoomed out to a "high" altitude where they can be seen in the surrounding landscape context, or from any chosen intermediate zoom level. 
programs running simultaneously, PVP boundaries or their centroid points can be digitized directly into an accurately geo-referenced GIS layer, thereby avoiding possible location, shape, and size errors introduced during the transfer of interpreted pools from marked-up photo prints to electronic map format. In addition, prints used in analog interpretation are not orthorectified or corrected for distortion, and features observed along their outer edges are typically not true to shape, size, or geographic location.

Although it is not statistically valid to compare the results of two analog towns with those of eight digital towns due to sample sizes, a general comparison of results from the two methods maybe helpful to other practitioners. The results of our study suggest that the 3D analog method of aerial photo interpretation may yield fewer PVP commission errors (i.e., false positives) than the 3D digital method (22.6 and39.2\% respectively). We believe the higher rate of commission error we experienced with the digital 3D methods is likely due to increased ability to detect shallow inundated areas that appear to be pools but have insufficient hydro period to support vernal pool biology. In our study, biological activity was found in 493 of 771 field-surveyed pools, representing an overall commission error of approximately $36 \%$. If we include the 38 pools that met the physical characteristics but contained no biological activity, our commission error would drop to approximately $30 \%$.

A portion of the commission errors we experienced involved field verification of pools that met the physical criteria but lacked biological use at the time of the field survey, or for various reasons, could not be thoroughly surveyed. (Table 3, Reasons 4 and 5). It is possible these pools could contain biological activity in some years thereby increasing our detection accuracy. A single visit in a single year may not be sufficient to conclude that a feature is not functioning as a vernal pool, given the annual variability in hydrology and breeding use known to occur (Burne and Lathrop 2008; Lathrop et al. 2005). Carpenter et al. (2011) report that commission errors from Massachusetts Seasonal Pool remote sensing efforts ranged from 0 to $50 \%$ for meeting the physical criteria and 4 to $61 \%$ for meeting the biological criteria, in a New Jersey mapping effort using 2D CIR digital aerial 
orthophotography, Lathrop et al.(2005)reported a $12 \%$ error of commission for meeting the physical criteria that the authors attributed to an inclination for the interpreters to err on the side of inclusion when mapping PVPs. That study also reported that only $22 \%$ of the pools meeting the physical criteria were found to contain biological activity, representing a comparable commission error of $78 \%$ using our criteria. Wu et al. (2014) utilized aerial imagery in conjunction with high resolution Light Detection and Ranging (LiDAR) data to locate PVPs in Massachusetts, reporting commission error rates in the range of 2.5 to $6.0 \%$ and an omission rate of $8.2 \%$, relative to that State's confirmed and potential vernal pool mapping data. However, no field verification component was completed for the PVPs in that study, which differs from our method of assessing both types of errors based on documented biological activity.

Arguably, two of the more important factors in the incidence of commission errors are interpreter experience and the assigned project goals. For example, if the remote sensing interpreter is aware of the full range of pools used by vernal pool species in a particular region and wishes to be comprehensive in the approach to finding potential pools, a high incidence of commission errors may be acceptable. Similar to other researchers (Lathrop et al. 2005) we preferred to err on the side of inclusion in our analyses.

We believe most omission errors result from the interpreter not being able to see the pools on the aerial imagery because they are obstructed from view by vegetation (tree limbs and foliage) or dark shadows being cast on the pool's location. The degree of shadowing is affected by the type, density and height of vegetation or other vertical objects, as well as the date and time-of-day the image is taken as they relate to the sun's angle in the sky. The image type and quality can also affect the degree of shadowing, and whether the area within the shadow has enough visible details to allow a correct interpretation (Tiner 1990; Burne and Lathrop 2008). Pools may also be missed because the surface hydrology was lacking when the aerial photos were taken. When mapping vernal pools, these factors pose potential problems for both analog and digital photography. 
Many forested areas within the 10 towns contained dense stands of evergreen trees, so we suspect that we missed many functioning vernal pools in our remote sensing efforts due to our inability to see the ground through the foliage depicted on the imagery. This potentially high rate of omission error is unfortunate, but it is an inherent limitation of the existing remote sensing methodologies using aerial photography (Tiner 1990; Lathrop et al. 2005; Van Meter et al.2008) and should be noted by natural resource managers and mapping programs looking to enhance inventories through field surveys in areas difficult to photo-interpret. Emerging technologies such as LiDAR and high-throughput computing or satellite imagery in semi-arid, open environments (Hass et al. 2009; Leonard et al. 2012;Wuet al. 2014) should help to address the potential for high levels of detection errors, though we believe that aerial photo interpretation and field verification will continue to be key components of the mapping process.

To further explore the potential magnitude of omission errors, we compared our remote sensing results with known vernal pools mapped in two additional Maine field surveys unrelated to VPMAP. These included a 16-ha forested area in Cumberland, and a 130-ha area of forests and fields in Orono. Digital 3D remote sensing correctly detected only two of the nine (22\%) known pools on the Cumberland property. The two that were correctly identified were in areas of deciduous forest cover, while the missed pools were in areas with dense coniferous cover (see Online Resource 4). For the Orono site, only three of the 23 (13\%) known vernal pools could be seen on the CIR stereo prints. The pools correctly detected on the aerial photos were in relatively open areas. The 20 missed pools were small $\left(\right.$ mean $45 \mathrm{~m}^{2}$ ) and/or located under dense coniferous forest.

The type of vegetative cover at a PVP was not a strong predictor of detection accuracy in our mixed models when compared with pool size and type. However, when vegetative cover was examined separately, our detection accuracy for pools in mixed or open cover was higher than pools in deciduous cover. Most likely this is an artifact of the higher commission error in the deciduous cover type. Larger and open pools maybe easier to accurately delineate because they contrast more with the surrounding landscape, and small wetlands are 
particularly difficult to photo-interpret through evergreen and mixed forest cover types (Tiner 1990; Tiner et al. 2015).

CVPs occurred in each of the primary NWI palustrine wetland classes we examined (forested, emergent, scrub-shrub, and open/unconsolidated bottom types), although CVPs were more commonly located in areas not mapped as wetlands by NWI (Table 5). Though the study was not specifically designed to correlate known pools with NWI mapping, this result is not surprising given that NWI data have shown mixed abilities to predict locations of vernal pools (Calhoun et al. 2003). Still, our results point to the need to consider NWI databases, and other mapping technologies such as LiDAR, as tools for corroborating remote and field surveys.

We believe that aerial photography is an extremely useful and cost-effective tool for mapping PVPs in New England or other similar glaciated landscapes. We suspect that errors in digitizing pool boundaries are much reduced using digital stereo plotters as compared to both 2D digital and 3D analog methods, and suggest that might be an appropriate subject for future study. We also predict that accuracy and thoroughness will improve as the quality of digital photography improves (i.e., higher resolution = better detail) and more researchers utilize digital stereo plotters. We stress the importance of using high-resolution CIR imagery taken in spring under optimal conditions, which include: cloudless days; a time of day with the highest possible sun angles to minimize shadows; little or no deciduous leaf emergence; little or no snow cover; and preferably directly following a normal but substantial precipitation event. Future studies specifically designed to assess omission errors would be important in better determining the actual remote-sensed detection rates for vernal pools in relation to pool size and forest cover type. Incorporating LiDAR technologies with stereo plotter methods could reduce both commission and omission errors. 
Acknowledgments

This is Maine Agriculture and Forestry Experiment Station Publication \#3466. This manuscript does not represent any official MDIFW finding or policy. 
References

Barrette J, August P, Golet F (2000) Accuracy assessment of wetland boundary delineation using aerial photography and digital orthophotography. Photogram Eng Remote Sens66:409-416

Brooks RT, Stone J, Lyons P (1998) An inventory of seasonal forest ponds on the Quabbin Reservoir watershed, Massachusetts. Northeast Nat 5:219-230

Burne MR (2001) Massachusetts aerial photo survey of potential vernal pools. Natural Heritage and Endangered Species Program, Department of Fisheries and Wildlife, Westborough

Burne MR, Lathrop RG(2008) Remote and field identification of vernal pools. In: Calhoun AJK, de Maynadier PK (eds) Science and conservation of vernal pools in northeastern North America. CRC Press, Boca Raton, pp $55-68$

Calhoun AJK, Walls TE, Stockwell SS, McCullough M (2003) Evaluating vernal pools as a basis for conservation strategies: a Maine case study.Wetlands23:70-81

Carpenter L, Stone J, Griffin CR (2011) Accuracy of aerial photography for locating seasonal (vernal) pools in Massachusetts. Wetlands 31: 573-581

Cowardin LM, Carter V, Golet FC, LaRoe ET (1979) Classification of wetlands and deep water habitats of the United States. U.S. Fish and Wildlife Service Biological Services Program, FWS/OBS-79/31

Hass EM, Bartholomé E, Combal B (2009) Time series analysis of optical remote sensing data for the mapping of temporary surface water bodies in sub-Saharan westernAfrica.JHydrol370:52-63

Jansujwicz JS, Calhoun AJK, Leahy J, Lilieholm RJ (2012) Using mixed methods to develop a frame-based private landowner typology. Soc Nat Resour: IntJ 26:945-961

Jansujwicz JS, Calhoun AJK, Lilieholm RJ (2013) The Maine Vernal Pool Mapping and Assessment Program: engaging municipal officials and private landowners in community-based citizen science. EnvironManag $52: 1369-1385$ 
Lathrop RG, Montesano P, Tesauro J, Zarate B (2005) Statewide mapping and assessment of vernal pools :a New Jersey casestudy. JEnviron Manag 76:230-238

Leonard PB, Baldwin RF, Homyack JA, Wigley TB (2012) Remote detection of small wetlands in the Atlantic coastal plain of North America: Local relief models, ground validation, and high throughput computing. ForEcol Manag 284:107-115

Maguire O, Armstrong RC, Benson JS, Streeter R, Paterson C, McDonald P, Salter N, East M, Webster M, Sheahan M, Young D (2012) Using high resolution digital aerial imagery interpreted in a 3-Ddigital GIS environment to map predefined plant communities in central-southern New South Wales. Cunninghamia 12:247-266

Morgan DE ,Calhoun AJK (2013) The Maine municipal guide to mapping and conserving vernal pools. University of Maine, Sustainability Solutions Initiative, Orono

Murillo-García FG, Alcántara-Ayala I, Ardizzone F, Cardinali M, Fiourucci F, Guzzetti F (2014) Satellite stereoscopic pair images of very high resolution: a step forward for the development of landslide inventories. Landslides 2:277-291

Oscarson DB, Calhoun AJK (2007) Developing vernal pool conservation plans at the local level using citizen-scientists. Wetlands 27:80-95

Stone JS (1992) Vernal pools in Massachusetts: aerial photographic identification, biological and physiographic characteristics, and state certification criteria. MS Thesis, University of Massachusetts, Amherst

Tiner RW Jr (1984) Wetlands of the United States: current status and recent trends. US Fish and Wildlife Service, Washington

Tiner RW Jr (1990) Use of high-altitude aerial photography for inventorying forested wetlands in the United States. ForEcolManag 33:593-604

Tiner RW Jr, Lang MW, Klemas VV (eds) (2015) Remote sensing of wetlands: applications and advances. CRC Press, Boca Rotan 
Van Meter R, Bailey LL, Campbell Grant EH (2008) Methods for estimating the amount of vernal pool habitat in the northeastern United States. Wetlands 28:585-593

Wu Q, Lane C, Liu H (2014) An effective method for detecting potential woodland vernal pools using high-resolution LiDAR data and aerial imagery. Remote Sens 6:11444-11467 